\title{
Reflections on the Evolving Triad Tutorial in a Postgraduate Art Studio
}

\author{
Dr Sarah Tripp
}

\begin{abstract}
This article traces the evolution of the 'triad tutorial'. The triad model, predominantly used in the training of counsellors and psychotherapists, was originally combined with the art school tutorial model in the context of the Edinburgh Sculpture Workshop to enhance critical discourse between studio holders. The resulting hybrid, the 'triad tutorial', was then adapted with postgraduate students on a Master's Fine Art course at a Scottish art school. Drawing on questionnaires from a small pilot study with students, the triad tutorial is described as an evolving model that has enhanced critical discourse between students, increased student confidence and introduced students to a new reciprocal structure of critique. Links are drawn between critical self-reflection, reciprocity and the sustainability of artistic practice. The development of the triad tutorial is described frankly using the autobiographic timeline of the author to present the model as evolving by trial and error and born of contingency rather than design.
\end{abstract}

\section{Article}

I am going to start by providing an overview of the development of the 'triad tutorial'. I will describe how the triad model, which is used in the training of counsellors and psychotherapists, was combined with the tutorial model before concentrating on the triad tutorial's adaptation on a Master's Fine Art (MFA) course at a Scottish art school. I am going to refer to a timeline in order to describe the evolution of the triad tutorial as the result of an ongoing reflective process that has been dependent on a range of contexts and opportunities, both in and out of art education. Opportunities have occurred during my career as an artist and teacher that functioned as a substrate in which the triad tutorial formed. The timeline, which spans my professional life from graduation in 1996 to the writing of this article, shows how opportunities and contexts interact over a period of years (figure 1).

By being frank about how the triad tutorial has come to be practiced on a MFA course-describing the coincidence and contingency - I am noting how the vicissitudes of practice and research yield unexpected hybrids. The triad tutorial was discovered rather than designed. 


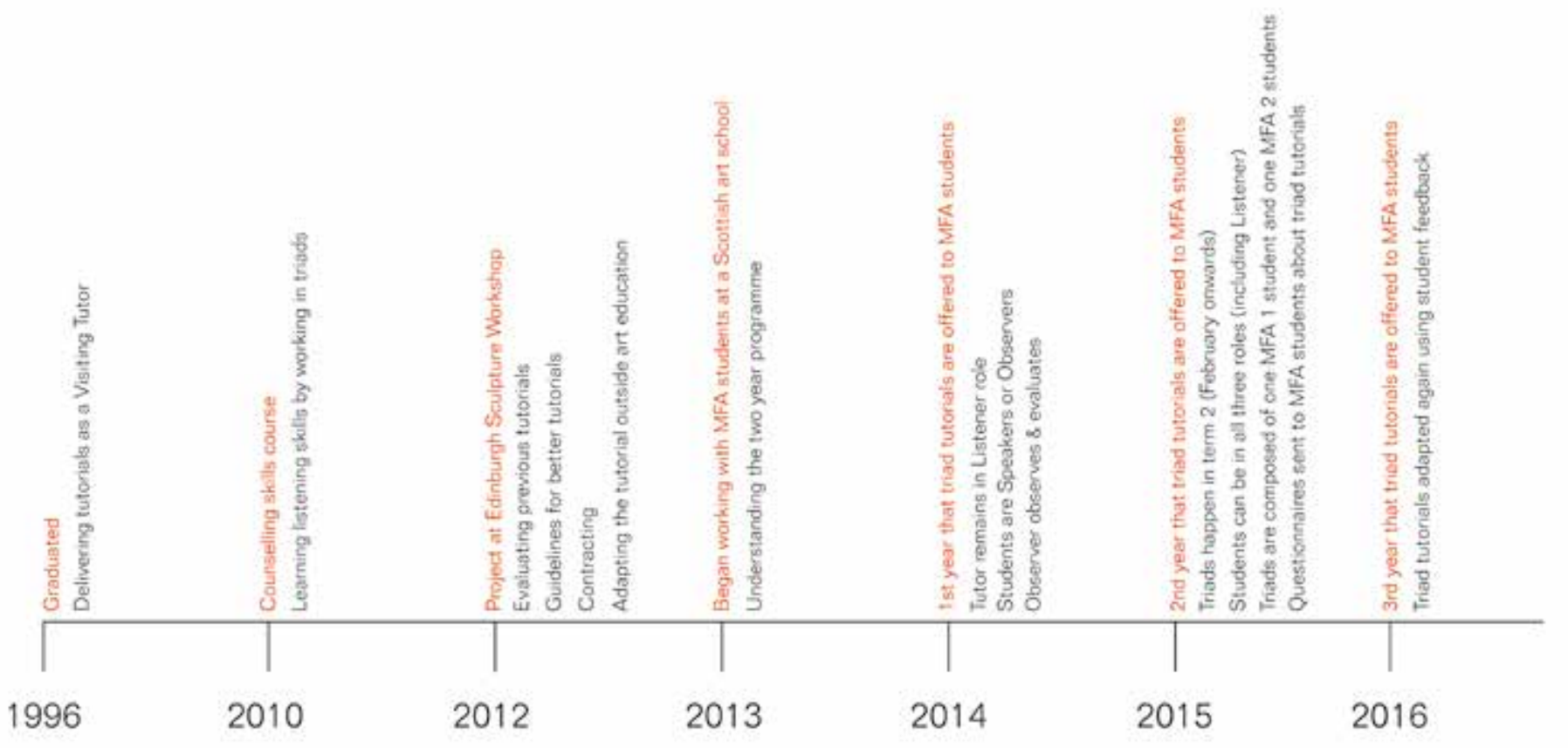

Figure 1: Timeline of the triad tutorial

In 1996, I graduated with a Masters of Art from a London art school. From the perspective of a graduating student, I understood a tutorial to be a conversation between a student and tutor in the student's studio space, lasting 45 minutes. This conversation could be about any aspect of the student's practice. Often roaming, subjects likely to be considered might include: the value of student's work, technical issues occurring during the production of a work, the habits of the practice, art criticism and cultural theory. This model of the tutorial had been prevalent from the 1960s onwards when a fundamental shift occurred in British Fine Art education away from teaching prearranged subject matter to tutorial conversations framing the student's practice within wider questions of contemporary art (Cornock, 1983, p.81).

Shortly after graduating, I was invited to work with undergraduate and postgraduate students as a visiting tutor at a number of art schools in the United Kingdom. I found myself delivering tutorials by drawing on my recent experiences of being a student. I discovered, if I was able to remain attentive and alert throughout the 45 minutes, tutorials could be both intellectually exhilarating and exhausting for both participants. I realised I had two aims over and above facilitating a useful discussion with the students: to moderate the intensity of this vital process and, because the experience can be very dynamic, ensure the student and I took time to reflect on the tutorial afterwards.

In 2010, when a friend started retraining as a psychotherapist, our conversations turned to a component of her course concerned with 'active listening' (Rogers and Farson, 1957). Curious about active listening, 
I joined a part-time, counselling skills course. The cohort consisted of people working in the caring professions: social workers, care workers, support workers and teachers who were either looking to improve their listening skills or considering a career in the talking therapies. The course lasted 12 months, the cohort met once a week and in each class we developed listening skills by working in 'triads'.

On this course, a triad consisted of three students occupying three different roles: the Speaker, the Listener and the Observer (figure 2). The Speaker explored an issue that was causing concern; the Listener actively listened; and the Observer observed without speaking and took notes. This followed a British triad model established in the late 1970s as the core of 'counselling practicum' by Gerard Egan in The Skilled Helper (Connor, 2001, p.6)

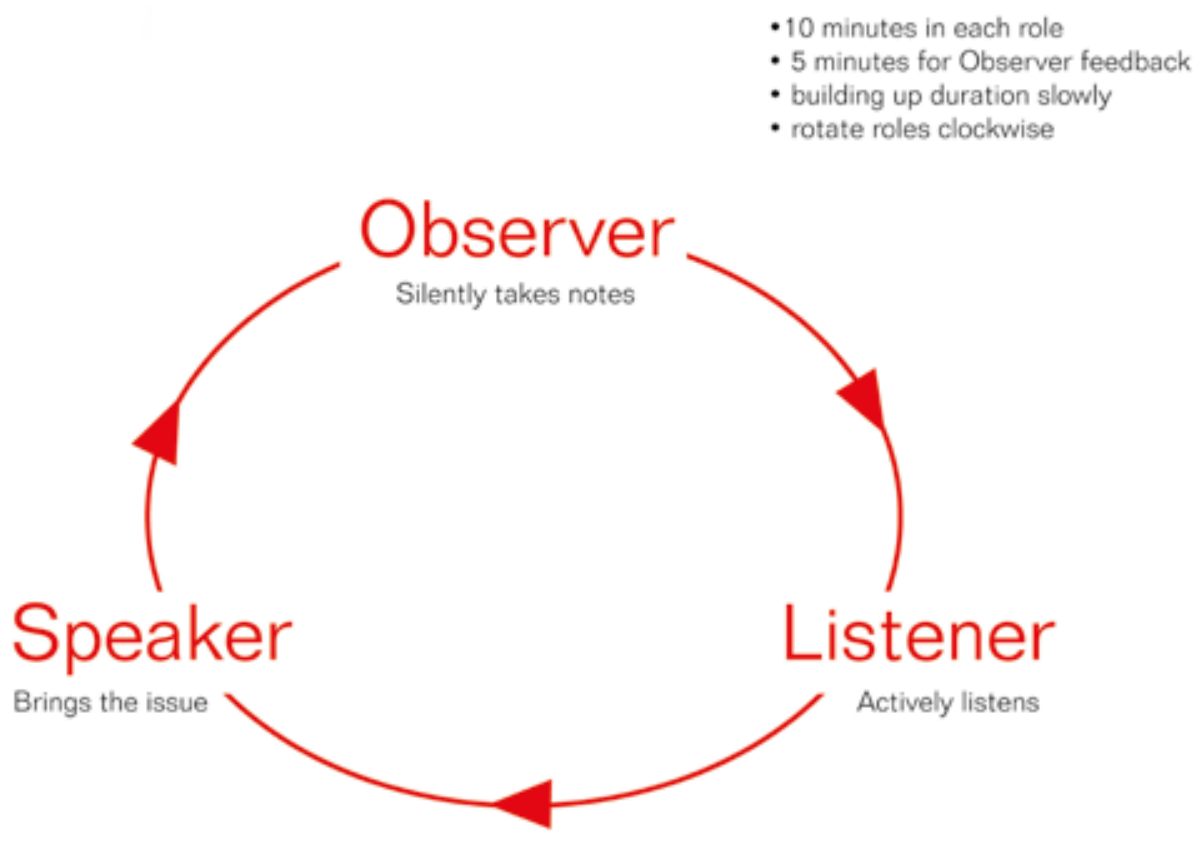

Figure 2: Triad structure used in the training of counsellors and psychotherapists

All our work in triads was strictly bounded by time. We began with very short sessions lasting 10 minutes and built up the duration. After, for example 10 minutes of active listening, the Listener and Speaker would turn to the silent Observer who provided feedback on what they had observed. Following feedback, the participants rotated positions changing roles: the Speaker became the Observer, the Listener became the Speaker and the Observer became the Listener. In each triad session we rotated roles three times permitting everyone the experience of all three perspectives.

The Triadic Method was born from the necessity of observing and recording interpersonal exchange and had been developed in the context of training and supervising counsellors. The Triadic Method, as 
originally outlined by Spice in 1976, permits the participants to experience different roles and, perhaps most importantly, the role of silent Observer provides insight and a record of what has occurred between the Speaker and the Listener. Silent observation also creates a particular mode of attention not immersed 'in the moment' of active listening or speaking.

The next marker on the timeline occurs in 2012 when I was invited to contribute to a project with studio holders at the Edinburgh Sculpture Workshop (ESW). This extract from the Press Release for the project (Mulholland, 2013) describes a festival culture as the context for the project:

The sites in which art is made and the myriad ways in which it is supported are increasingly overlooked, festival culture being fixated with the quantifiable outcomes of homo economicus: the tourist spectacle, the brand, the product. Workshops and studios such as Edinburgh Sculpture Workshop are more often concerned with non-economic work, work that can't be easily quantified, with the process of learning through action. To make art and money involves a combination of shadow work and shiftwork, the patterns of which largely remain invisible. The expansion of Edinburgh Sculpture Workshop's facilities and studios should encourage us to reconsider the ways in which publicly funded arts organisations might best facilitate comprehensive approaches to production rather than novel ways of fetishising consumption.

The phrase 'facilitate comprehensive approaches to production' describes the challenge I faced on graduation, a challenge faced by many recent graduates: if you are able to secure the practical conditions necessary to sustain your practice - studio, materials and time - how do you begin to secure and maintain a critical, self-reflective discourse as well? Without a course and tutors to structure and maintain critical discourse, in-depth and serious discussions on practice between artists tend to be rare. How do you sustain mutual, critical dialogue around practice after art school ends?

I began planning a workshop with the studio holders at ESW to resolve the model of the tutorial with the model of the triad in order to find a means of reflecting on practice using a reciprocal, sustainable structure. A group of 12 studio holders, who had a wide variety of practices, worked with me on a two phase workshop. I began by asking the group for their personal experiences of tutorials in art school, asking the following questions: What aspects of tutorials were helpful? What aspects were destructive? Were tutorials inspiring? What conditions might be necessary to have a helpful or inspiring tutorial? 
I wrote their responses onto a whiteboard recording their reflections and preferences that were then used to build guidelines for a better tutorial. The group were asked to initial the whiteboard, confirming their agreement with the guidelines (this technique, called 'contracting' (Lawton, pp.31-32), was adapted from the training of counsellors and psychotherapists). In the second half of the workshop, I introduced the triad model and suggested how we might fuse the triad with the tutorial to sustain critical dialogue between studio holders. After further discussion I demonstrated to the group how the triad tutorial could function. We then split into four groups of three and tried out the proposed model using the guidelines established by participants. Figure 3 illustrates the roles adopted by studio holders during the workshop.

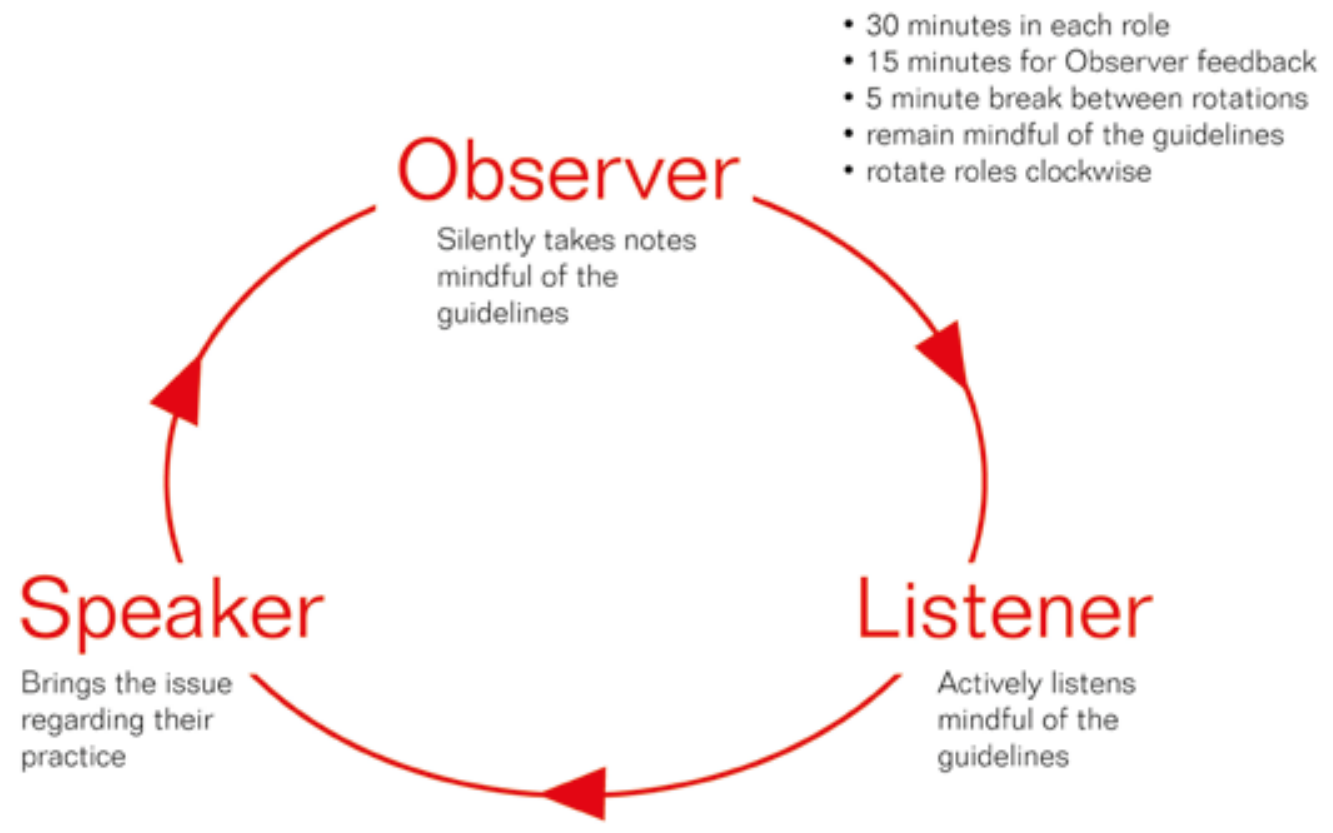

Figure 3: Triad structure used at the Edinburgh Sculpture Workshop

In 2013, I was employed by a Scottish art school to work two days per week with students on a MFA course there. However, before I describe this event on the timeline I want to differentiate postgraduate from undergraduate fine art learning because postgraduate learning has been the pedagogical context in which I have experienced the triad tutorial evolve. I propose that the student who joins an institution to begin postgraduate study has an established artistic practice. The student may have just graduated from an undergraduate course or, they are returning to education following years of independent practice, but what they have in common is an established practice. Whereas the student embarking on undergraduate study may have artistic habits, preferences, expertise and knowledge, but these are unlikely to constitute an established practice. The work the undergraduate course does is put the fundamentals of practice in place. Undergraduate fine art students are building a pattern of habits called practice, whereas postgraduate 
students are adjusting, enhancing and sometimes dismantling and then rebuilding those habits. I cannot explore this further within this remit of this article but I ask you to keep this differentiation in mind as I explore the triad tutorial in the postgraduate context of a MFA course.

After spending 2013 becoming familiar with this two-year postgraduate course I proposed offering triad tutorials to the students. In February of 2014, the students were invited to sign up in pairs for a joint tutorial with me. They were asked to choose a partner from either year group who they felt they had some affinity with: a common ethos, an alignment of practice, a collaborative project underway or a joint endeavour planned. Our administrator adapted our tutorial sign-up sheets to accommodate two student names per tutorial, lengthening the tutorial to two and a half hours. Unlike the ESW, there was no discussion about the value of tutorials or the drawing up of guidelines before the triads began. At the start of each triad, we convened in one of the student's studio spaces, I simply explained the roles, emphasised the importance of time keeping and careful note taking, and we began (figure 4).

I took the role of Listener (the Tutor's perspective), one student took the role of Speaker (the Student's perspective) and the other student took the role of Observer (silently observing and taking notes). 35 minutes were spent conducting the first tutorial with a subsequent ten minutes allowed for Observer feedback. We took a ten-minute break, then moved to the second student's space and swapped roles. Speaker became Observer, and Observer became Speaker. A further 35 minutes were spent on the second tutorial with 10 minutes of Observer feedback. The Observer was asked to consider making notes on anything they observed of potential value to them or the Speaker, anything they would have contributed if they were the Listener, any comments about how the tutorial was conducted and any non-verbal exchanges. At the time, I offered these ideas as suggestions and I emphasised the importance of the Observer making notes in any form that was easy for them and most appropriate to the content of the observation. For example, drawing might be as valid as writing depending on the nature of the observation.

From the perspective of tutor, operating outside the social relations of the cohort, I was struck by what the sign-up sheet revealed. Once student names were added to the sign-up sheet, I realised I had little idea how they had chosen their partners. Consequently, before beginning each triad, I asked both students to say why they had chosen to share the triad. Often they were planning extra-curricular projects or in dialogue about practice in the social realm that was largely obscured from me. 


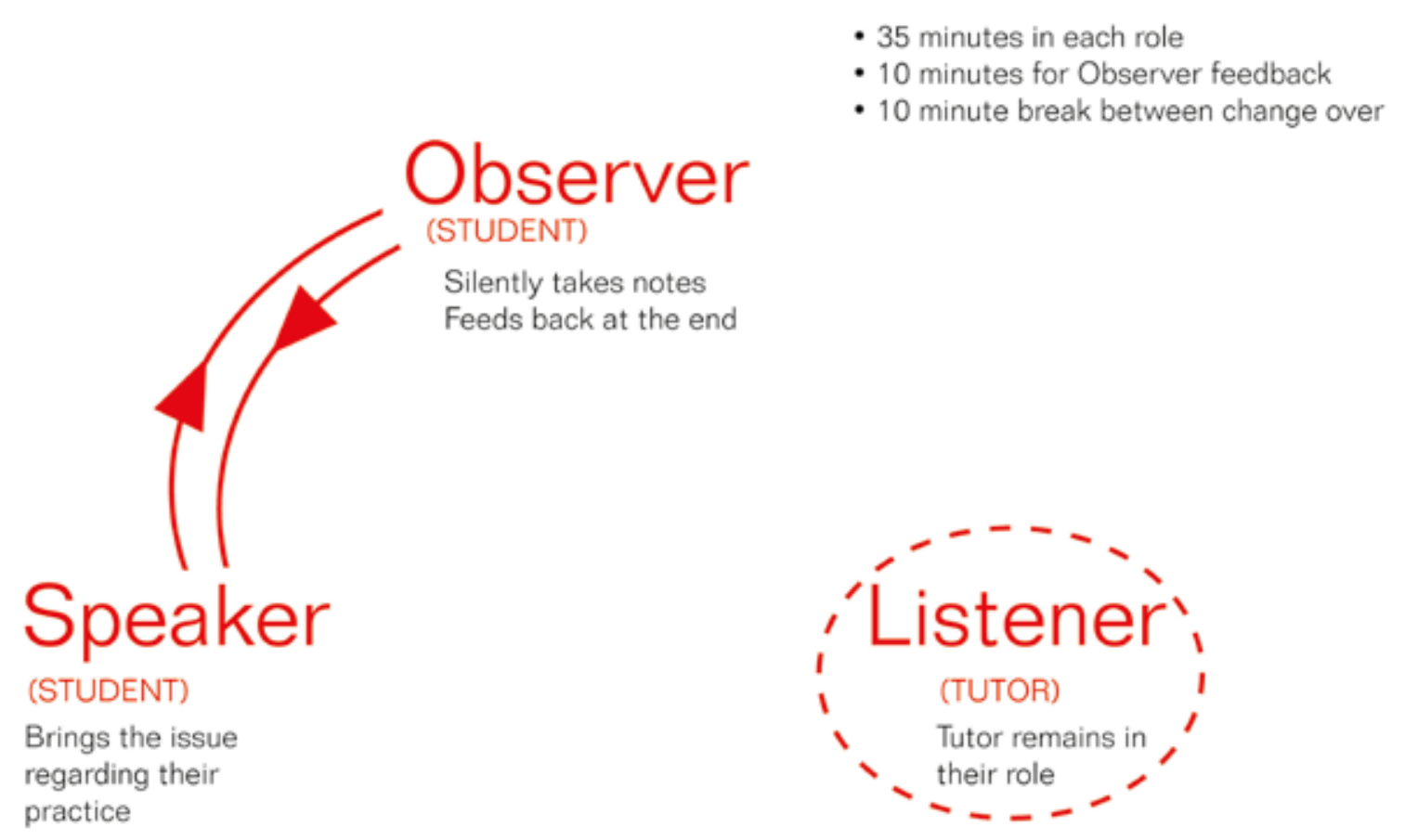

Figure 4: The first triad structure used on the Master's Fine Art course in 2014

At this point in time I was in weekly dialogue with the students in my role as their tutor so feedback on working in triads was given after each triad was completed or offered casually around the studios. There were enough positive comments to suggest that the triad tutorials were worth pursuing once or twice a year as a supplement to the more familiar tutorial model.

In spring 2015, during this second round of triads, further adaptations were made in response to the specific timetable of the MFA course and the experience of the previous year. Triad tutorials were scheduled for the second term (January onwards) because by this point in the academic year the incoming first year students (MFA 1) were settled in the city (many of our students being international) and familiar with each other, and the current second year students (MFA 2), to interact confidently. The most important change made to triads in 2015 was inviting students to adopt the Listener role (be the Tutor) if they wished and the many of them grasped the opportunity with both hands. This invitation was a response to the confidence the MFA 2 students showed when working with the triad model during the previous year. Once in the role of Listener, they were able to, in a sense, remake the tutorial by being the kind of tutor they would prefer or aspire to be. I (the Tutor) never occupied the role of Speaker but the pair of students could adopt the combinations of Speaker and Listen or Speaker and Observer. Once both the students had chosen their roles for the tutorial, I took the third role (figure 5). If the students wanted to be Speaker and Listener then I became Observer by default, if they wanted to be Speaker and Observer, I became Listener. 


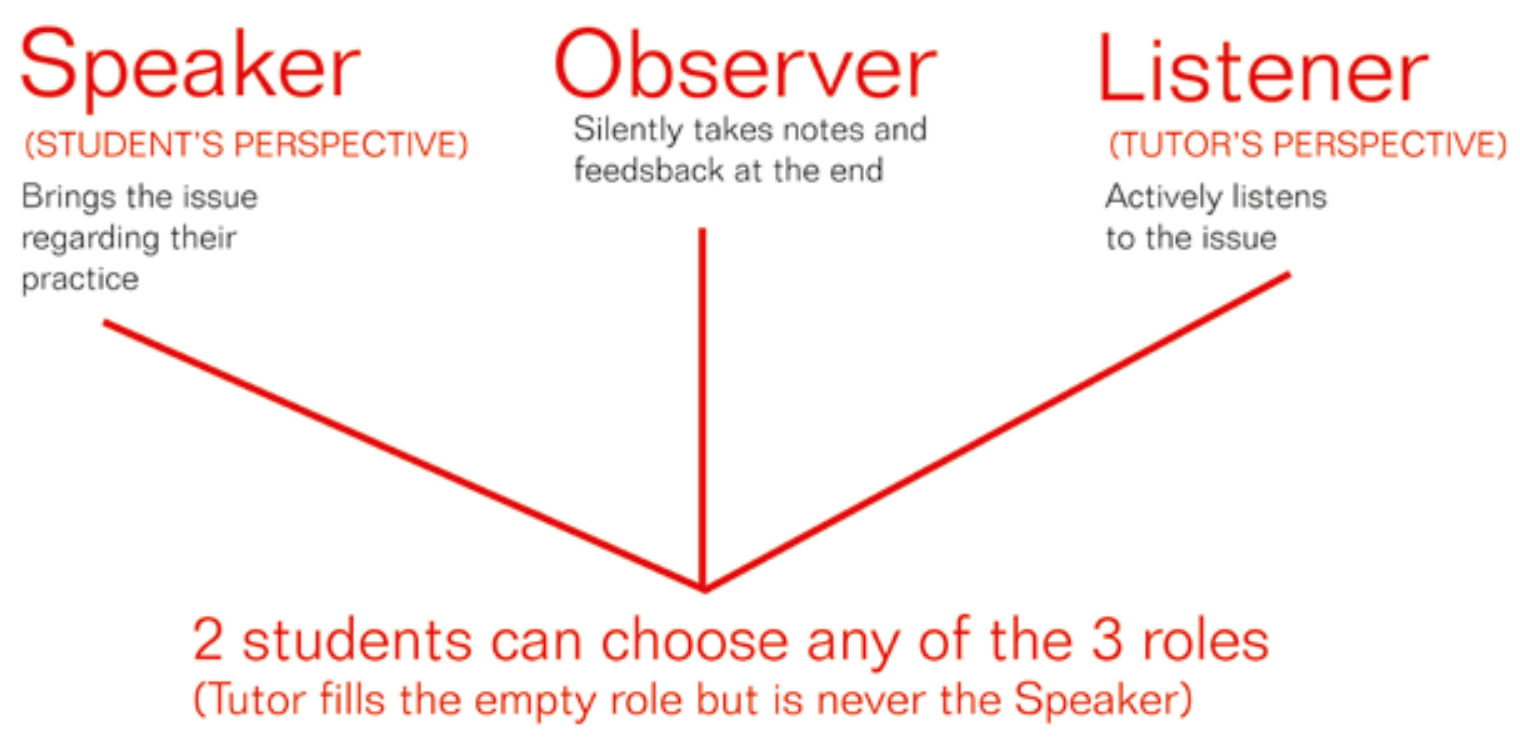

Figure 5: The second triad structure used on the Master's Fine Art course in 2015

This, the second year of offering triad tutorials, yielded particularly dynamic tutorials. I suggest, on reflection, that this was in part due to the fact that some of the MFA 1 students had worked in triads during 2014, were aware of what a triad tutorial was and therefore were able to use the model with more confidence.

In late 2015, I emailed a short questionnaire to six students who had participated in the tutorial triads over subsequent years. The questions were written to elicit qualitative responses from the students: to find out how they experienced each role within a triad and to gather their suggestions. The students were selected based on the likelihood of getting useful feedback on the process. Please note that when quoting from these emailed interviews I have reproduced my questions in order to frame the students' responses and anonymised the student's names.

Toshi graduated from the MFA course in June 2015. While in the second year of the course he participated in a triad tutorial with Phillip (from MFA 1 cohort). Toshi and Phillip were a predictable pairing: both had been exploring painting as a consistent activity within their multi-stranded practices. Here Toshi comments on experiencing the roles of Listener and Observer: 


\section{Q: What was your experience in the role of Listener?}

I feel that the questions I pose to the other were simultaneously posed to myself because it's very hard to fully adopt a listener role. In so doing, sometimes there's a meta-moment when the question is projected and bounced back. Certain questions I had for myself were resolved simply by listening to someone else articulating the same problem.

\section{Q: What was your experience in the role of Observer?}

This is very interesting process because the observer sees everything from the outside so not only is he/she noting the content of the conservation but also its movement. Who is speaking more? Where are the misunderstandings and contradictions? What is the recurring narrative behind the work.

Toshi's triad partner Phillip was instantly at ease with the triad model, despite being in the MFA 1 cohort and thus less familiar with the course. Phillip's answers express his affinity with Toshi's practice and the challenges of observing, he wrote:

\section{Q: What made you sign up for a triad tutorial?}

The opportunity to add the additional voice and opinion of someone who I found to have similar interests with my practice.

Q: What was your experience in the role of Speaker?

It was very easy since it was the role I was familiar with.

Q: What was your experience in the role of Listener?

I personally enjoyed this role since it allowed me to ask questions and engage in a proactive way with someone else's practice.

Q: What was your experience in the role of Observer?

This role was slightly challenging since I had no previous experience doing anything of the sort. I found it to be a very worthwhile exercise since it forced me to pay close attention and listen closely to both listener and speaker. This I think is extremely important nowadays, especially for anyone considering a teaching career in the future.

Kelly is about to graduate from the MFA 2 cohort but at the time of answering my questionnaire was part of the MFA 1 cohort and participated in a triad with Misha (then part of the MFA 2 cohort). I suggested that Kelly and Misha consider a triad because I perceived overlaps between their interest in moving image and disembodied voices. Kelly describes the inside/outside dynamic between students and tutors and how she was able to almost replay the tutorial, comparing the Observer's feedback to watching a film of the tutorial. She wrote: 


\section{Q: What was your experience in the role of Speaker?}

Though I was conscious there was a third person involved documenting everything I said, as an outsider in the equation, I did not find it off-putting. I was comfortable in this familiar position of talking about my work. I found it refreshing having a discussion with a fellow student, someone who is in the same boat as me rather than the usual outside tutor.

\section{Q: What was your experience in the role of Listener?}

Being in the role usually adopted by the tutor helped me think about listening. I was conscious of trying to listen to everything Misha said and keep up with her. I made notes in attempt to bring her back to certain points so they were not lost. I was left considering my own behavior in tutorials - to avoid rambling, speak slower and be more concise.

\section{Q: What was your experience in the role of Observer?}

Due to our choice, neither Misha nor myself got to experience this role. The tutor took on the observer role. I did experience the Tutor's observer's notes, which were extremely beneficial. Hearing what we had discussed (from the Tutor's perspective) helped me understand the tutorial. I noticed at points I may not have been listening or may have misinterpreted something Misha said or even miscommunicated my own points. The Tutor's observations were like we had filmed ourselves and played it back, highlighting my behavior and treatment towards talking, listening and observing. I have consciously taken this awareness into my 'normal' tutorials.

The other perspective on this triad with Kelly is provided here by Misha. Misha graduated in June 2015 and had already participated in a triad in 2014 with another student when she was in her first year of the course. Here Misha offers her perspective on the roles of Listener, Observer and Speaker over the two years of the course:

\section{Q: What was your experience in the role of Listener?}

I think this role is very interesting as you spend most of your time on the MFA talking about your own practice but not too much actually listening pointedly to others talking about theirs. Even in crits, you are essentially listening to other people's interpretations of art works but rarely from the artist themselves (I mean as part of the curriculum). In this role you can listen carefully to how other artists articulate their ideas and methods.

Also, I think it is good for students to be forced into an act of altruism, however small. A good listener should listen, ultimately, for the benefit for the other student, which is sometimes lacking in an art school environment. Also, it is very difficult to ask pertinent questions about another artist's practice and not just reel off a list of things that the work might remind you of. This role is a good lesson in how to cut to the crux of a problem, and to say it aloud.

\section{Q: What was your experience in the role of Observer?}

This is quite a strange and privileged position to be in. There is a voyeuristic element to this role that helps assert the analytical part of the brain, without the pressure of having to simultaneously respond to the person talking. It feels in some way as though the pressure is off because you do not have to 
respond immediately and you have the advantage of reading body language and other signs that might not be immediately apparent when you are talking to someone. I also felt as though my notes didn't have to be too succinct or revelatory. It felt as though just reading back what had been said, as in a stream of consciousness, could be just as effective and helpful to the group as anything else. I suppose this is because when we talk, we rarely actually hear what we say. Or, rather, we are using a part of our brains that is reactive and instinctive and sometimes hidden to us in less taxing environments.

The notes that you end up writing highlight areas of a conversation about art that you clearly find more interesting or useful than others, which obviously tells you more about your own practice and the way you analyse information than anything else.

\section{Q: What was your experience in the role of Speaker?}

I think that it is really useful to speak about your work from within the confines of your own studio as it helps solidify the work that you do in that space. When you invite people into that space it intensifies your understanding of how others might perceive your work, as the environment feeds naturally into the conversation. In the second triad with Kelly, I felt that I could lead the conversation confidently and take markers from the objects and colours in her studio at times when I thought she might have been struggling to explain her ideas. My confidence in this triad also came from a knowledge and experience that I had gained from working through similar problems in my own practice.

In February 2016, I conducted triads with the MFA students for the third year. Further adaptations were made building on the feedback provided to the questionnaire that also asked, 'How could the triads be better?' In 2016, students were encouraged to choose their partner from the other year group: an MFA 1 student would partner an MFA 2 student or visa versa, but this was not a stipulation. The triad tutorials composed of students from both cohorts turned out to be more critically robust. MFA 1 students have all the benefits of listening to the MFA 2 students experience of the course. MFA 2 students also help orientate MFA 1 students within the triad model. Each tutorial was shortened to 30 minutes in order to extend Observer feedback to 10 minutes and a following ten minutes allocated for open discussion between all three participants. This makes the running time of each triad tutorial two hours: 15 minutes introducing the model to the students; 30 minutes for the first tutorial; 20 minutes Observer feedback and open discussion; 5 minute break; 30 minutes second tutorial; 20 minutes Observer feedback. The Observer provides a copy of their notes to the Speaker and the students are encouraged to continue their dialogue at their leisure and follow up with further suggestions after they have had a few days to reflect.

I would like to acknowledge the courage of the students who have helped me develop triad tutorials.

Working in a triad has been an entirely new experience, for me and the students, one that required a leap of faith. At the start of the questionnaire I asked, 'What were your reservations/doubts/fears about engaging in the triad tutorial?' Toshi answered: 
With a third party involved, the tutorial moves out of a private space between two persons into a more public one since the observer can feel like an audience. I was worried that the session would become too performative for it to be productive. Being observed can also make people edit what they say.

Misha answered:

In the first triad, my main fears stemmed from my insecurities as an artist: what my work was about, how could I move it successfully from still to moving image, how the rest of my peer group judged my work? I also felt nervous about performing well as part of the triad. Would I be able to give any helpful feedback to Kelly? What was Kelly going to ask me about? Could I explain my ideas? Ultimately, I had no idea what I was doing and was scared that this would be revealed during the tutorial.

Kelly answered:

I feared not being able to help adequately. I felt slightly daunted about being on the other side of the discussion where I was a listener - I had doubts as to whether I would have anything valuable to contribute to the discussion.

And, when Phillip was asked if he had any reservations he answered, 'None'.

The responses to the questionnaire indicate that triads provide students with opportunities to listen more carefully to critical discourse, share the intimacy of the tutorial experience with a peer and to occupy the role of tutor. Tutorials between tutor and student are one of the most valuable tools in studio-based learning but by augmenting the closed 'couple' form of the tutorial with an observer, in-depth reflection can be reciprocated between students during a structured encounter.

One of the central challenge of postgraduate fine art learning is how to work with, and against, the habits of practice established before the student arrives. If students have the courage to work in triads, the model's rotating perspectives can encourage more carefully listening to the critical discourse that surrounds their practice on the course.

I now want to return to the related themes of reciprocity, critical discourse and sustainability. This article describes the evolution of the 'triad tutorial' over a number of years. Throughout this time my aim was not to design and test an adaptation of the traditional tutorial but to engage the students I worked with in a deeper process of reflection on practice through and with their cohort and to remain healthily dissatisfied with my teaching practice.

In 2015, I paused to email a questionnaire to triad participants in order to create a moment for my own 
reflection on what had become a feature of my teaching practice and a small component of the postgraduate course where I work. What I noticed from their replies is in one sense obvious: deep and critical reflection on practice was a valued part of the students' experiences. The course outline describes critical selfreflection as essential and a condition necessary for a sustainable practice after the course. This reflection is given written form as a 'Self-reflective Statement' written by students. These documents describe the student's work and practice from their perspective and often combine personal realisation with conceptual and theoretical insight in their subjective voice. These realisations, like flagpoles in a continuously shifting territory, orientate both student and tutor within the student's practice. I want to propose that the quality of critical self-reflection, which is arguably vital for sustaining practice, may be enhanced by reciprocity. That the experience of being listened to actively and critically and of listening actively and critically, when shared between students, enables self-reflection.

Most students learn to value the critique they receive and most staff realise that the strength of a cohort's discourse dictates the quality of their practices. What the triads make evident, or perhaps demonstrate, is that critical self-reflection is enhanced by taking the role of a Listener (tutor), and being the Listener to a fellow student is as valuable an experience as being the Speaker (student). When participating in triad tutorials students quickly realise that their ability to critically respond to a fellow student's practice or work enhances their own processes of critical self-reflection: students are surprised by how much there is to gain from being the Listener. As Misha pointed out: 'A good listener should listen, ultimately, for the benefit for the other student, which is sometimes lacking in an art school environment. Also, it is very difficult to ask pertinent questions about another artist's practice and not just reel off a list of things that the work might remind you of. This role is a good lesson in how to cut to the crux of a problem, and to say it aloud.'

What I want to suggest is that triad tutorials, like standard tutor/student tutorials, might be a live form of critical self-reflection. However, what the triad adds is a representative of the cohort, which utilizes reciprocal feeling in a way that the presence of just the tutor does not. It could be argued that the relationship between the tutor and student may be balanced, responsive or even equal but one thing it is not is reciprocal: the tutor does not receive critique on their work or practice from the student. The reciprocity introduced by the triad structure makes tangible to the students that offering active listening and robust critique informs their own critical self-reflection. Students who engage confidently with group critiques gain a tacit awareness of this principle but students who are more reticent to speak in front of a group often miss out. 
Like any pilot study this one outlines further research to be undertaken. Since writing this article, I have conducted triad tutorials with postgraduate students studying outside the United Kingdom where the learning environment and pedagogical culture is different, further research is needed to reflect on this experience. The triad could also be of particular value to supervisors and students working together on doctorate research where the intensity of supervision could be shared with a triad made up from fellow doctoral candidates or a second supervisor. The role of the Observer also needs further reflection and analysis: specifically the function of the Observer's notes and how the Observer reflects, reiterates and distils critical exchange between Speaker and Listener. Finally, the question of how to prepare students for the triad tutorial experience needs further development. Taking all participating students through a workshop to troubleshoot the traditional tutorial before embarking on triads might empower the students to use the model more confidently from the start.

\section{References:}

Cornock, S., 1983. Towards a Methodology for Students of Fine Art. Journal of Art \& Design Education, [online] Vol 2, No 1. Available at: <http://onlinelibrary.wiley.com/doi/10.1111/j.1476-8070.1983.tb00021.x/ pdf> (accessed: 17 July 2016).

Connor, M., 2001. Training the Counsellor: An Integrative Model London: Routledge.

Lawton, B., 2000. 'A Very Exposing Affair': Explorations in Counsellors' Supervisory Relationships. In: B. Lawton, C. Feltham, ed. 2000. Taking Supervision Forward: Enquiries and Trends in Counselling and Psychotherapy. London: Sage Publishing. Ch.2.

Mulholland, N., 2013. Shift Happens. Research Catalogue: An International Database for Artistic Research, [e-journal] Available through: Research Catalogue: an International Database for Artistic Research website $<$ https://www.researchcatalogue.net/view/28573/28574> (accessed 26 February 2016).

Rogers, C. R., Farson, R. E., 1957. Active Listening. Chicago: University of Chicago, Industrial Relations Center.

Spice, C. G., 1976. A Leader's Guide to the Triadic Model of Supervision Training Professionals to Anticipate the Challenges of the Future. [pdf] Pittsburgh: Department of Counselor Education, University of Pittsburgh. Available at: <http://files.eric.ed.gov/fulltext/ED126396.pdf> (accessed: 2 June 2016).

Spice, C. G., Spice, W. H., 1976. A Triadic Method of Supervision in the Training of Counselors and Counseling Supervisors. Counselor Education and Supervision. [pdf] Vol 15, Issue 4. Available at: <http:// onlinelibrary.wiley.com/doi/10.1002/j.1556-6978.1976.tb02002.x/pdf> (accessed: 17 July 2016).

Tripp, S., 2015. Questions Regarding Triad Tutorials. (email). Message to Toshi, Phillip, Kelly, Misha. Sent 2 November 2015: 16:43.

Toshi, 2015. Re: Questions Regarding Triad Tutorials. (email). Message to Sarah Tripp. Sent 2 November 2015: 18:23. 
Phillip, 2015. Re: Questions Regarding Triad Tutorials. (email). Message to Sarah Tripp. Sent 4 November 2015: 15:07.

Kelly, 2015. Re: Questions Regarding Triad Tutorials. (email). Message to Sarah Tripp. Sent 5 November 2015: 16:40.

Misha, 2015. Re: Questions Regarding Triad Tutorials. (email). Message to Sarah Tripp. Sent 5 November 2015: $12: 42$. 